\title{
The Mere Categorization Effect: How the Presence of Categories Increases Choosers' Perceptions of Assortment Variety and Outcome Satisfaction
}

\author{
CASSIE MOGILNER \\ TAMAR RUDNICK \\ SHEENA S. IYENGAR*
}

\begin{abstract}
What is the effect of option categorization on choosers' satisfaction? A combination of field and laboratory experiments reveals that the mere presence of categories, irrespective of their content, positively influences the satisfaction of choosers who are unfamiliar with the choice domain. This "mere categorization effect" is driven by a greater number of categories signaling greater variety among the available options, which allows for a sense of self-determination from choosing. This effect, however, is attenuated for choosers who are familiar with the choice domain, who do not rely on the presence of categories to perceive the variety available.
\end{abstract}

$\mathrm{I}_{\mathrm{p}}^{\mathrm{n}}$ magine shoppers browsing the magazine rack in a supermarket. They study rows upon rows of glossy pages, colorful pictures, and splashy headlines. They wander the aisle among hundreds of publications grouped under different category headings. Picture the magazines on the rack: Under "Fashion" there is the ultrathick issue of Vogue. Under "Current Events" there is a copy of Newsweek. Under "Music" there is the most recent Rolling Stone. Watch the shoppers pick magazines from a set of hundreds. Did the category labels_-"Fashion," "Current Events," "Music"influence the shoppers' choices? Did the very presence of

*Cassie Mogilner is a marketing $\mathrm{PhD}$ candidate at Stanford University, Graduate School of Business, 518 Memorial Way, Stanford, CA 94305 (mogilner_cassie@gsb.stanford.edu). Tamar Rudnick is a research assistant at the Graduate School of Business, Columbia University, New York, NY 10027 (tamar.rudnick@gmail.com). Sheena Iyengar is a professor of management at the Graduate School of Business, Columbia University, 3022 Broadway, 714 Uris Hall, New York, NY 10027 (ss957@columbia.edu). The authors would like to thank the National Science Foundation and Time Distribution Services for contributing the funds and resources supporting the studies reported in this investigation. Baba Shiv and Jennifer Aaker are thanked for their generous feedback during the various stages of this article's development. Additionally, the authors would like to thank Cristy Rasco, John Remarek, and Snowden Wright for their invaluable research assistance.

John Deighton served as editor and Stephen Nowlis served as associate editor for this article.

Electronically published June 11, 2008 categories affect their satisfaction with their magazine selections?

We sought answers to these questions by observing customers as they shopped the magazine aisles of a northeastern supermarket chain. The 10 branches of the chain where we conducted our observations varied in the number of magazine options (331-664, $M=575)$ and the number of magazine categories $(18-26, M=23)$, which were unrelated $(r(10)=-.26, \mathrm{NS})$. Although each of the store displays identified such categories as "Fashion and Beauty," "Health and Fitness," and "Entertainment," the retailer had flexibility in deciding whether to further categorize the display to include such categories as "Women's General Interest," "Sports," and "Music." We observed 391 shoppers as they exited the magazine aisle (50\% women, age range $30-50$ years) and asked them to participate in a short survey. Shoppers reported on a 100-point scale their perceptions of the variety offered by the magazine selection and their levels of satisfaction with their shopping experience. The results showed that while the actual number of magazine options had little impact ( $\beta=.04, t=.66, \mathrm{NS})$, the number of categories used to partition the display positively influenced perceptions of variety $(\beta=.18, t=3.44, p=$ $.001)$, which in turn led to greater customer satisfaction $(\beta=.49, t=11.00, p<.001)$.

Expanding on the observations from our exploratory field study, the following investigation more closely examines the relationship between the presence of categories and con- 
sumers' subjective experiences of choosing. In particular, the studies reported in this investigation examine the effect of mere categorization, in terms of the number and content of category labels, on chooser satisfaction. In a series of two experiments conducted in the choice domains of magazines and gourmet coffee, we show that the mere presence of a greater number of categories leads to increased chooser satisfaction, irrespective of the information contained in the category labels. This "mere categorization effect" occurs by increasing choosers' perceptions of variety, which increases their feelings of self-determination. In addition to the implications for retailers, this research also pertains to extant work on perceived variety (e.g., Broniarczyk, Hoyer, and McAlister 1998; Hoch, Bradlow, and Wansink 1999; Kahn and Wansink 2004) and assortment size (e.g., Chernev 2003b; Iyengar and Lepper 2000). Next we develop our conceptual model and hypotheses.

\section{THE PSYCHOLOGY OF MERE CATEGORIZATION}

Although our exploratory field study suggests that a greater number of categories leads to higher customer satisfaction, the reasons for the effect remain in question. Previous research has shown that the content of category labels can inform choosers about the attributes of the items grouped under each heading (Alba, Hutchinson, and Lynch 1991; Bettman 1979; Howard and Sheth 1969; Huber and Kline 1991; Johnson and Payne 1985; Nedungadi 1990; Roberts and Lattin 1991). The categorization of options may therefore help choosers refine their set of options (Chakravarti and Janiszewski 2003; Diehl, Kornish, and Lynch 2003; Ratneshwar and Shocker 1991; Rosen 1978; Zhang and Fitzsimons 1999). Indeed, Diehl et al. (2003) found that choosers who had access to a screening device that rank ordered a subset of the available options made better-quality choices. If categories benefit choosers by directing them to their preferred option within an assortment, then the positive effect of categories we observed on supermarket customers' satisfaction would require the labels articulating those categories to be informative.

Perhaps the mere presence of categories also communicates something to affect choosers' satisfaction. It has been shown that categories serve to identify differences between items (Heit and Rubinstein 1994; Lassaline 1996; Rosch 2002; Sloutsky 2003) and that the processing of categories operates at a very basic level (Rosch 1976). Research in linguistics demonstrates that items represented by words with different classifiers are perceived to be more dissimilar than those same items represented by words with the same classifier (Schmitt and Zhang 1998). According to the principle that people assume information is conveyed in every act of communication (Clark 1985; Grice 1975), options grouped under the same category label are likely to be perceived as more similar, whereas options grouped under different category labels are likely to be perceived as more different. The presentation of categories, therefore, will likely lead consumers to infer differences between the available options. Instances have even been documented where consumers inferred meaning from marketers' inclusion of meaningless information. In particular, consumers were found to infer brand value from marketers' mere mention of a brand attribute, even though the attribute was known to be meaningless (Carpenter, Glazer, and Nakamoto 1994). Similarly, we propose that the presence of categories might serve as a cue that signals differences between options to consumers, even when the actual options and their differences remain constant. The more categories articulated to consumers, the greater variety they may perceive.

This proposed role of categories is that of a perceptual cue rather than an information-based cognitive process. Prior research suggests that the informational content of category labels can facilitate preference identification (Alba et al. 1991; Bettman 1979; Chakravarti and Janiszewski 2003; Howard and Sheth 1969; Huber and Kline 1991; Johnson and Payne 1985; Nedungadi 1990; Ratneshwar and Shocker 1991; Roberts and Lattin 1991; Rosen 1978). We propose that category labels alone, irrespective of whether they are informative, will signal to consumers differences between the options.

Prior research suggests that individuals are more willing to choose among seemingly distinct options but are less likely to choose when the differences between the available options are minimal (Dhar 1997). Choosers avoid relatively homogenous choice sets in order to not undergo the conflict of choosing among indistinguishable options for which the trade-offs are unclear (Festinger 1964; Tversky and Shafir 1992). The inability to perceive differences among the available options may therefore thwart individuals' feelings of control from choosing, and it is this decreased sense of selfdetermination that results in lower satisfaction. The choosing experience can give individuals a sense of autonomy only if it fosters "people's choicefulness or volition" (Ryan and Deci 2006, 1576). Thus, an assortment of seemingly similar options would decrease individuals' perceived ability to act in accordance with their values and interests, detracting from their enjoyment of the outcome (Deci and Ryan 1985; Ryan and Deci 2000).

This may help explain consumers' attraction to extensively varied assortments. As a potential source for feelings of self-determination, assortments that offer extensive variety have been found to draw greater in-store traffic, to offer between-store advantage, and to increase the quantity of products consumed (Broniarczyk et al. 1998; Hoch et al. 1999; Iyengar and Lepper 2000; Kahn and Wansink 2004). Consumers' perceptions of variety, however, are not necessarily contingent on the actual number of options present. By manipulating display features (such as shelf space and messiness) and by featuring popular options, marketers can appeal to consumers' desire for variety without actually offering more options (Broniarczyk et al. 1998; Hoch et al. 1999; Kahn and Wansink 2004). This suggests that a display cue such as categories might also increase choosers' perceptions of variety and their subsequent satisfaction. 
Yet the benefits gained from categories may not be experienced equally by every chooser. For choosers familiar enough with the choice domain to possess established preferences, whom we will call "preference matchers," the process of choosing is both more directed (Russo and Leclerc 1994) and less cognitively burdensome (Chernev 2003a, 2003b). For a preference matcher, choosing only entails either locating the item previously evaluated as most favorable (Lingle and Ostrom 1979; Lynch, Marmorstein, and Weigold 1988; Wright 1975) or identifying the item that best matches one's ideal attribute combination (Coupey, Irwin, and Payne 1998; Hauser and Wernerfelt 1990). Preference matchers' familiarity with the choice domain expedites their differentiation between options (Alba and Hutchinson 1987), allowing them to perceive variety within an assortment without the aid of a display cue. Therefore, preference matchers perceive the variety offered in a choice set to be independent of the choice set's categorization. They can choose without a display cue and still be happy with their choice.

In contrast, consumers in unfamiliar choice domains, whom we will call "preference constructors," have yet to identify their preferred attribute combinations. They face the task of forming their preferences during the choosing process (Bettman, Luce, and Payne 1998; Carpenter and Nakamoto 1989). With limited knowledge of the choice set, preference constructors rely on information found in the choice environment to determine their preferences, which makes display cues highly influential (Dodd, Pinkleton, and Gustafson 1996; Fischhoff 1991; Fischhoff, Slovic, and Lichtenstein 1980; Hoch and Ha 1986; Hoeffler and Ariely 1999; Levin and Gaeth 1988; Lynch, Chakravarti, and Mitra 1991). We predict that preference constructors, who lack the expertise to distinguish between the available options (Alba and Hutchinson 1987), will draw on the display cue of categories to perceive the variety available and to garner satisfaction from choice.

We hypothesize that only preference constructors will gain satisfaction from the number of categories in a choice set, whereas preference matchers will not depend on categorization in order to experience the value of choice. More formally:

H1a: The number of categories will have a positive effect on satisfaction for preference constructors but not for preference matchers.

H1b: For preference constructors, perceived variety will drive the positive effect of category number on satisfaction.

Two experiments were conducted to test these hypotheses. Experiment 1 examines both the influence of category number on choosers' satisfaction and the mediating role of perceived variety, providing support for hypotheses 1a and 1b. Experiment 2 extends these findings by showing not only that the effect among preference constructors does not require the content of the category labels to be informative but also that it is driven by the sense of self-determi- nation experienced when choosing from a seemingly varied assortment.

\section{EXPERIMENT 1: THE MAGAZINE STUDY}

Experiment 1 built on the categorization effect found in the preliminary field study by testing it in a controlled laboratory environment with the number and content of options held constant. Participants in this experiment were randomly assigned to one of four conditions in the 2 (chooser type: preference matcher vs. preference constructor) $\times 2$ (categorization: three categories vs. 18 categories) between-subjects design.

\section{Method}

Participants. Sixty-one students from Columbia University responded to fliers posted around campus offering $\$ 10$ as compensation for their participation in a 30-minute marketing research study. The group of participants comprised approximately equal numbers of men (48\%) and women $(52 \%)$ who ranged in age from 18 to 48 years ( $M=22$ years). Participants represented a variety of ethnic backgrounds, including white (49\%), Asian (22\%), African American (12\%), Latino (10\%), and others (7\%).

Magazine Display. The experiment was conducted in a university laboratory designed to simulate a well-stocked supermarket magazine aisle. One hundred and forty-four different magazines were displayed on 9-by-12-foot magazine racks on two adjacent walls.

To test the moderating role of choosers' familiarity with the choice domain, a pilot study was conducted to ensure that there was sufficient variability in students' familiarity with the provided options. When asked to examine a list of 77 magazines, the 34 pilot study participants each listed the titles they were familiar with (which ranged from three to 28 magazines, $M=9.44$ ). The participants marked 53\% of the magazines as being familiar (39\% being one of three that they read regularly) and $47 \%$ as unfamiliar. Given this variation in familiarity, all 77 magazines were included in the experiment's display.

Two additional pilot studies were conducted to establish categorical classifications that participants would consider both familiar and appealing. In the first pilot, 20 students were asked to "list the first 10 magazine categories that come to mind" and to allot one, two, and three points to their third, second, and first most preferred categories, respectively. Participants generated a total of 95 categories, including the three broad categories of "Men's," "Women's," and "General Interest" (each of which received between one and 18 points, $M=12$ ) and 18 more specific categories (e.g., "Cooking," "Auto," and "Sports," each of which received between one and 75 points, $M=20$ ), which could be subsumed into the three broader categories.

In the second pilot, 60 students were presented with the 30 magazine categories used by the supermarket chain investigated in the preliminary field study and were instructed 
to "rank order the top three magazine categories from which you are most likely to buy a magazine." Participants' rankings confirmed that the most popular categories in this consumer context matched the categories generated in the previous pilot study. For instance, the supermarket magazine categories "Fashion," "Sports," "Music," and "Computers" were among the highest-ranked, while "Men's," "Women's," and "General Interest" each received at least one top ranking.

Results from these pilot studies helped us design the two conditions for the magazine display used in the experiment. While all participants viewed the same magazine options, the same number of magazines, and identical arrangements of the magazines, the options were grouped into either three general categories or 18 more specific categories. In both conditions, 18 3-by-12-inch plaques displaying the category headings were attached to the racks under the third, sixth, and ninth row shelves, following the supermarket magazine aisle model. In the three-category condition, each category was represented by six plaques, whereas in the 18-category condition, each of the category headings appeared only once. Figure 1 illustrates the magazine displays from both conditions.

Procedure. An experimenter led participants one at a time into a room containing the magazine display and prompted them to select a magazine, delivering the following narrative: "We are running this study in conjunction with World Distributions, a large magazine distribution company. They are interested in consumers' magazine preferences. I will give you a few minutes to look around and pick a magazine."

The instructions then varied to manipulate participants' familiarity with their choice set. Participants who were ran- domly assigned to the preference constructor conditions were instructed to "choose a magazine that you don't regularly read. You will then be asked to complete a survey on this unfamiliar magazine." In contrast, the instructions for participants who were assigned to the preference matcher conditions continued, "Choose a magazine that you regularly read. You will then be asked to complete a survey on this familiar magazine." A manipulation check confirmed that all preference constructors chose an unfamiliar magazine and that all preference matchers chose a familiar magazine.

After receiving the instructions, the participants were left alone to peruse the magazine display. After 3 minutes (the average amount of time the supermarket customers spent in the magazine aisles in the field study), the experimenter reentered the room and asked, "Have you chosen a magazine? Bring your magazine, and you will complete a questionnaire in the next room."

Chooser Satisfaction. To assess participants' satisfaction with their chosen magazines, they were asked to rate on a 10 -point scale $(1=$ not at all satisfied, $10=$ extremely satisfied), "How satisfied are you with your choice?" Ancillary analyses revealed that satisfaction was not significantly influenced by the number of magazines perused, the amount of time required by participants to make their selections, or the perusal style employed.

Perceived Variety. Three items (with the third item reverse scored) were averaged to create an index of perceived variety $(\alpha=.76)$. Participants were asked on a 10 point scale $(1=$ no choice at all, $10=$ a lot of choice $)$, "How much choice do you feel you were offered in terms

FIGURE 1

MAGAZINE DISPLAYS

THREE-CATEGORY MAGAZINE DISPLAY

\begin{tabular}{|c|c|c|c|c|c|}
\hline Men's & Men's & $\begin{array}{l}\text { General } \\
\text { Interest }\end{array}$ & $\begin{array}{l}\text { General } \\
\text { Interest }\end{array}$ & Women's & Women's \\
\hline Men's & Men's & $\begin{array}{l}\text { General } \\
\text { Interest }\end{array}$ & $\begin{array}{l}\text { General } \\
\text { Interest }\end{array}$ & Women's & Women's \\
\hline Men's & Men's & $\begin{array}{l}\text { General } \\
\text { Interest }\end{array}$ & $\begin{array}{l}\text { General } \\
\text { Interest }\end{array}$ & Women's & Women's \\
\hline
\end{tabular}

EIGHTEEN-CATEGORY MAGAZINE DISPLAY

\begin{tabular}{|c|c|c|c|c|c|}
\hline $\begin{array}{c}\text { Hunting \& } \\
\text { Fishing }\end{array}$ & Sports & Food & Business & $\begin{array}{c}\text { Women's } \\
\text { Health \& } \\
\text { Fitness }\end{array}$ & Hairdo \\
\hline $\begin{array}{c}\text { Men's } \\
\text { General } \\
\text { Interest }\end{array}$ & $\begin{array}{c}\text { Men's } \\
\text { Health \& } \\
\text { Fitness }\end{array}$ & Music & $\begin{array}{c}\text { Science \& } \\
\text { Technology }\end{array}$ & $\begin{array}{c}\text { Women's } \\
\text { Fashion }\end{array}$ & Bridal \\
\hline Auto & Motorcycle & Crossword & Computing & $\begin{array}{c}\text { Home } \\
\text { Decorating }\end{array}$ & Craft \\
\hline
\end{tabular}


of the magazine selection?" Drawing from prior perceivedvariety research (Broniarczyk et al. 1998; Hoch et al. 1999; Kahn and Wansink 2004), we also asked participants on a 10 -point scale $(1=$ very little variety, $10=\mathrm{a}$ lot of variety), "How much variety do you think there was in the magazine display?" Finally, participants were asked, "How similar do you think all of the magazines in the display were to each other?" $(1=$ not at all similar, $10=$ extremely similar). Ancillary analyses revealed that participants' perceptions of variety were not significantly influenced by the number of magazines perused, the amount of time required by participants to make their selections, or the perusal style employed.

\section{Results}

The number of categories into which the choice set was divided affected choosers' satisfaction with their selections, but only for preference constructors (i.e., choosers charged with the task of constructing their preferences while choosing). For preference matchers (i.e., choosers charged with the task of scanning the choice set to match their preexisting preferences), the number of categories did not affect their satisfaction with their selections. A 2 (chooser type) $\times 2$ (number of categories) ANOVA was conducted on chooser satisfaction, revealing (1) a significant main effect for chooser type $(F(1,57)=11.44, p=.001)$, with preference matchers $(M=8.20)$ reporting greater satisfaction than preference constructors $(M=6.77)$; (2) no main effect for number of categories $(F(1,57)=1.72, \mathrm{NS})$; and $(3)$ a significant interaction $(F(1,57)=3.90, p=.05)$. As hypothesized (hypothesis 1a), subsequent planned contrasts showed that the categorization effect occurred among preference constructors but not among preference matchers, with preference constructors reporting significantly higher satisfaction in the 18-category condition $(M=7.50)$ than in the three-category condition $(M=6.18 ; F(1,57)=5.47$, $p<.05)$. Preference matchers showed no differences in satisfaction across category conditions $\left(M_{3}=8.33\right.$ vs. $M_{18}=$ $8.07, F(1,57)=.22$, NS). In the three-category condition, preference constructors were significantly less satisfied than preference matchers $(F(1,57)=15.07, p<.001)$; however, in the 18-category condition, no differences in satisfaction were observed between preference constructors and pref- erence matchers $(F(1,57)=.95, \mathrm{NS})$. See table 1 for means and standard deviations.

The number of categories also affected choosers' perceptions of variety, but only for preference constructors. A 2 (chooser type) $\times 2$ (number of categories) ANOVA was conducted on perceived variety, revealing (1) no main effect for chooser type $(F(1,57)=.31, \mathrm{NS}) ;(2)$ a significant main effect for number of categories $(F(1,57)=5.49, p<.05)$, with 18 categories $(M=7.26)$ creating higher perceptions of variety than three categories $(M=6.29)$; and (3) a significant interaction $(F(1,57)=3.88, p=.05)$. Planned contrasts showed that while no differences were observed in preference matchers' perceptions of variety between the 18-category condition $(M=6.76)$ and the three-category condition $(M=6.60 ; F(1,57)=.07, \mathrm{NS})$, preference constructors in the 18-category condition $(M=7.81)$ perceived significantly more variety than did those in the three-category condition $(M=6.01 ; F(1,57)=9.41, p<.01)$. Perceived variety did not vary by chooser type in the threecategory condition $(F(1,57)=1.05, \mathrm{NS})$, and it did so only marginally in the 18-category condition $(F(1,57)=3.04$, $p<.10)$.

We predicted that the number of categories delineating an assortment would positively affect choosers' satisfaction by signaling the variety available. We further predicted that this effect would occur only among preference constructors-those who rely on information in the choice display to identify their preferred options. Conversely, we predicted that preference matchers' ability to perceive variance among the available options would be independent of the number of categories present. To test this hypothesis (hypothesis 1b), we conducted separate mediation analyses for preference constructors and preference matchers. For preference constructors, satisfaction was first regressed on the number of categories $(\beta=.34, t=1.96, p<.10)$. Next, perceived variety was regressed on the number of categories $(\beta=$ $.46, t=2.79, p<.01)$, and then satisfaction was regressed on perceived variety $(\beta=.60, t=4.01, p<.001)$. When satisfaction was regressed on both the number of categories and perceived variety, the effect of category number $(\beta=.09, t=.50, \mathrm{NS})$ significantly decreased, while the effect of perceived variety remained significant $(\beta=.56$, $t=3.29, p<.01$; Sobel $z=2.26, p<.05)$. This suggests that the effect of category number on preference construc-

TABLE 1

EXPERIMENT 1 RESULTS

\begin{tabular}{|c|c|c|c|c|}
\hline & \multicolumn{2}{|c|}{ Three categories } & \multicolumn{2}{|c|}{ Eighteen categories } \\
\hline & $\begin{array}{l}\text { Preference } \\
\text { constructors }\end{array}$ & $\begin{array}{l}\text { Preference } \\
\text { matchers }\end{array}$ & $\begin{array}{l}\text { Preference } \\
\text { constructors }\end{array}$ & $\begin{array}{l}\text { Preference } \\
\text { matchers }\end{array}$ \\
\hline $\begin{array}{l}\text { Satisfaction } \\
\text { Perceived variety }\end{array}$ & $\begin{array}{l}6.18^{\mathrm{a}, \mathrm{b}}(2.21) \\
6.01^{\mathrm{a}}(2.11)\end{array}$ & $\begin{array}{l}8.33^{b}(1.23) \\
6.60(1.39)\end{array}$ & $\begin{array}{l}7.50^{\mathrm{a}}(1.34) \\
7.81^{\mathrm{a}}(1.29)\end{array}$ & $\begin{array}{l}8.07(1.10) \\
6.76(1.49)\end{array}$ \\
\hline
\end{tabular}

NOTE.-Numbers in parentheses are standard deviations. Within each row, means with matching superscripted letters are significantly different at the $p \leq .05$ significance level. 
tors' satisfaction is mediated by perceived variety. In contrast, identical analyses conducted for preference matchers showed that the number of categories had no effect on either satisfaction $(\beta=-.18, t=-.63, \mathrm{NS})$ or perceived variety ( $\beta=.06, t=.30, \mathrm{NS})$ and that only perceived variety had an effect on satisfaction $(\beta=.39, t=2.25, p<.05)$.

Notably, we also conducted an experiment similar to this one but with chooser type measured (i.e., participants were asked whether their chosen magazine was one that they read regularly) rather than manipulated and found the same pattern of results. Therefore, consistent with prior research, we found that choosers' perceptions of variety positively influence their satisfaction (Broniarczyk et al. 1998; Hoch et al. 1999). We further found that choosers who are insufficiently familiar with the choice set to immediately perceive the available variety use the display cue of category number to determine the variety offered. Taken together, the findings from experiment 1 suggest that the presence of more rather than fewer categories may play a significant role in enabling choosers-particularly those choosing from among unfamiliar options - to differentiate between the available options, engendering greater satisfaction with their choice.

\section{Discussion}

When confronted by a large assortment, choosers' satisfaction may have less to do with the number of available options and more to do with the perceived differences among the options. Those choosers who search the options to match preexisting preferences possess a familiarity with the choice set that allows them to perceive variety in the assortment and achieve satisfaction with their chosen outcomes, even in the absence of categorical cues. In contrast, choosers who must engage in preference construction while making sense of a large, unfamiliar choice set face a more challenging choosing exercise. Those choosers must rely on the external cue of categories to recognize the variety inherent in the assortment. They experience satisfaction from choosing once they perceive differences among the options. Categories, therefore, give preference constructors the opportunity to achieve the same levels of satisfaction from choosing as preference matchers by influencing the key mediating variable: perceived variety.

Although the categorization effect (i.e., the positive impact of the number of categories on choosers' satisfaction) has been convincingly demonstrated in both an externally valid field setting and a controlled laboratory setting, the "mereness" of the effect remains untested. Experiment 2 was conducted to further investigate the means by which categories achieve their effect, namely whether categories are effective because the labels teach choosers to identify the options' distinguishing attributes or because they merely signal to choosers that differences must exist between items belonging to different groupings, in which case even uninformative category labels should increase perceptions of variety and satisfaction. By varying the information contained in the category labels, the following experiment tests the prediction that the mere presence of categories will pos- itively influence preference constructors' satisfaction. Furthermore, the experiment will test whether this effect is driven by increased feelings of self-determination garnered from choosing among a seemingly varied assortment. In addition to accumulating support for hypotheses $1 \mathrm{a}$ and $1 \mathrm{~b}$, experiment 2 will also test the following hypotheses:

H2: For preference constructors, the positive effect of category number on satisfaction will occur for both informative and uninformative category labels.

H3: For preference constructors, feelings of self-determination will drive the effect of perceived variety on satisfaction.

\section{EXPERIMENT 2: THE COFFEE STUDY}

Experiment 2 manipulated the information contained in the category labels to test the hypothesis that both informative and uninformative category labels increase preference constructors' choice satisfaction. The experiment followed a 4 (category: no categories vs. 10 informative categories vs. 10 somewhat uninformative categories vs. 10 completely uninformative categories) $\times 2$ (chooser type: preference matcher vs. preference constructor) betweensubjects design, where categorization was manipulated and chooser type was measured.

Additionally, experiment 2 was conducted in the product domain of coffee, which afforded two benefits. First, because both the preliminary field study and experiment 1 used magazines as the stimuli, this experiment tested the generalizability of the effect across product domains. Second, it allowed us to hold participants' actual choice outcomes constant without their knowledge. Although the participants believed they consumed their chosen option, in actuality they were all given the same coffee flavor. Participants' reported satisfaction consequently reflected the same item for all participants, permitting a truly controlled examination of the effect of categorization on satisfaction.

\section{Method}

Participants. A female research assistant holding coffee menus randomly approached people sitting at tables in a food court at Stanford University. Those approached were asked if they would be interested in participating in a consumer coffee study in which participants would be given $\$ 5$ as compensation for selecting a coffee from the menu and then answering a brief questionnaire about their selections. Of the approximately 150 individuals approached, 138 agreed.

Of the participants, $53 \%$ were male and $47 \%$ were female, and they ranged in age from 17 to 66 years $(M=26$ years). The ethnic composition was $59 \%$ white, $27 \%$ Asian, 6\% Hispanic, 5\% African American, and 3\% other.

Categories. Participants were randomly given one of four menus presenting 50 coffee flavors (listed in the same 
order across conditions) and were instructed to "please peruse this menu of coffee options, and choose one that you would like to taste." The menus, which were made of 11by-17-inch laminated sheets, listed 50 names of coffee flavors drawn from those offered by Starbucks, Peet's Coffee and Tea, and a local gourmet coffee shop.

The coffee options were either uncategorized or divided into 10 categories with labels that were informative, somewhat uninformative, or completely uninformative. The informative category labels specified attributes of the coffee flavors, such as "Complex," "Spicy," "Nutty," "Mild," "Earthy," and so on. The labels in the two uninformative category conditions provided no actual information about the options within the categories. However, if choosers were motivated to find meaning in the labels, they likely could have in the somewhat uninformative condition, which grouped the coffees by names of fabricated coffee shops such as "The Gathering," "Java Joe's," "Coffee Time," "The Coffee Shop," and "The Living Room." The category labels in the completely uninformative condition were based simply on letters from the alphabet: "Category A," "Category B," "Category C," and so on. See the appendix for the menus presented in the four 10-category conditions.

To ensure that the attribute-based category labels were perceived as more informative than both the coffee-shopbased category labels and the alphabet-based category labels, a pilot study was conducted among 45 participants from the same subject pool. The pilot study participants were presented with one of the three 10-category menus and were asked to rate on a 7-point scale $(1=$ not informative at all, $7=$ very informative) how informative the category labels were. An ANOVA revealed that the category labels varied significantly in their informativeness $(F(1,42)=9.86, p<.001)$. Contrasts showed that the attribute-based category labels $(M=3.93$; SD $=1.91)$ were perceived as significantly more informative than either the coffee-shop-based category labels $(M=2.53$; SD $=.74$, $t(42)=-2.87, p=.006)$ or the alphabet-based category labels $(M=1.80 ; \mathrm{SD}=1.08, t(42)=-4.37, p<.001)$. The coffee-shop-based labels and the alphabet-based labels did not differ in their perceived informativeness $(t(42)=$ $-1.50, p>.10)$.

All participants were given 1.5 minutes to peruse the menu. Afterward they reported their chosen coffee to the research assistant, who wrote it down and stated that she would return with it in a few minutes. When there were multiple participants at a single table, the research assistant took all of their orders at the same time. (The number of people at a table ranged from one to four and did not affect subsequent responses on the perceived variety or satisfaction measures.) After taking the participants' orders, the research assistant left for approximately 5 minutes and returned with a Styrofoam cup one-quarter full of coffee. As the coffee was handed to the participant, the research assistant stated the name of his or her selected coffee flavor, which was also handwritten on the cup. Unbeknownst to the participants, all participants were served the same coffee flavor: Ethio- pian Fancy from Peet's Coffee and Tea. To ensure that participants believed they had received their chosen coffee, they were asked at the end of the study what they thought the study was about and whether they were suspicious of anything in the study. Six participants reported suspecting that all participants received the same coffee to taste. These participants were removed from the analyses, which left a sample size of 132. After tasting their coffee, participants completed a three-page questionnaire that included the following measures.

Chooser Type. This study classified preference matchers as those participants who were more familiar than average with the choice domain and preference constructors as those who were less familiar than average with the choice domain. Familiarity was measured with three items $(\alpha=$ .92). One gauged the extent of participants' exposure to the product category by asking on a 7-point scale $(1=$ not at all frequently, 7 = very frequently), "How frequently do you drink coffee?" The other two tapped participants' expertise by asking on 7 -point scales $(1=$ not at all, $7=$ very much), "To what extent do you consider yourself a coffee drinker?" and "To what extent can you distinguish between types of coffee?"

Chooser Satisfaction. To measure choosers' satisfaction, participants were asked on a 7 -point scale $(1=$ not at all, $7=$ very satisfied), "How satisfied are you with your coffee choice?" and "How good does your coffee taste?" Responses on these two items were averaged to create an index of outcome satisfaction $(\alpha=.92)$.

Perceived Variety. To measure participants' ability to perceive variety in the assortment, the participants were asked on 7 -point scales $(1=$ not at all, $7=$ very much), "How different were the coffee options from each other?" and "How similar were the coffee options to each other?" The latter item was reverse scored. To measure how distinct they believed their chosen option to be, they were asked on the same scale, "To what extent do you feel that the coffee you chose is distinct from the other types of coffee you did not choose?" These three items were averaged to create an index of perceived variety $(\alpha=.71)$.

Self-Determination. To measure the degree to which their choosing experiences contributed to feelings of selfdetermination, participants were presented with four items from the Intrinsic Motivation Inventory that pertained to choice (Deci et al. 1994; Ryan 1982; Ryan, Koestner, and Deci 1991). On a 7 -point scale $(1=$ not at all true, $7=$ very true), participants were asked to state how true the following statements were for them: "I believe I had some choice about selecting this particular coffee," "I selected this particular coffee because I wanted to," "I selected this particular coffee because I had no choice," and "I selected this particular coffee because I had to." Responses to the first two items and the reverse scores of the second two items were averaged to create the index of perceived self-determination $(\alpha=.70)$. 
TABLE 2

EXPERIMENT 2 RESULTS

\begin{tabular}{|c|c|c|c|c|c|c|c|c|}
\hline \multirow[b]{3}{*}{ Chooser type } & \multirow{2}{*}{\multicolumn{2}{|c|}{ Zero categories }} & \multicolumn{6}{|c|}{ Ten categories } \\
\hline & & & \multicolumn{2}{|c|}{ Attribute-based } & \multicolumn{2}{|c|}{ Coffee-shop-based } & \multicolumn{2}{|c|}{ Alphabet-based } \\
\hline & $\begin{array}{l}\text { Preference } \\
\text { constructor }\end{array}$ & $\begin{array}{c}\text { Preference } \\
\text { matcher }\end{array}$ & $\begin{array}{l}\text { Preference } \\
\text { constructor }\end{array}$ & $\begin{array}{c}\text { Preference } \\
\text { matcher }\end{array}$ & $\begin{array}{l}\text { Preference } \\
\text { constructor }\end{array}$ & $\begin{array}{c}\text { Preference } \\
\text { matcher }\end{array}$ & $\begin{array}{l}\text { Preference } \\
\text { constructor }\end{array}$ & $\begin{array}{c}\text { Preference } \\
\text { matcher }\end{array}$ \\
\hline Satisfactio & $3.53^{a, b, c, d}(1.51)$ & $4.80^{a}(1.42)$ & $4.47^{\mathrm{b}}(1.37)$ & $4.17(1.54)$ & $4.73^{\mathrm{c}}(1.36)$ & $5.06(1.09)$ & $4.87^{\mathrm{d}}(1.41)$ & $4.41(1.30)$ \\
\hline Perceived vari & $3.77^{a, b, c, d}(1.64)$ & $4.84^{\mathrm{a}}(.78)$ & $4.75^{\mathrm{b}}(.72)$ & $4.44(1.06)$ & $5.04^{c}(1.19)$ & $4.71(1.26)$ & $4.71^{\mathrm{d}}(1.05)$ & $4.98(.98)$ \\
\hline Preference identification & $2.36(1.92)$ & $2.77(1.53)$ & $4.03^{\mathrm{a}, \mathrm{b}}(1.92)$ & $3.80(1.69)$ & $2.50^{\mathrm{a}}(2.00)$ & $3.35(1.85)$ & $2.47^{\mathrm{b}}(.97)$ & $2.87(2.05)$ \\
\hline
\end{tabular}

NOTE.-Numbers in parentheses represent standard deviations. Within each row, means with matching superscripted letters are significantly different at the $p \leq .05$ significance level.

Manipulation Check and Alternative Account. Although a pilot study was conducted to demonstrate that perceptions of category-label informativeness varied across the category conditions, as an additional check of the manipulation the experiment participants were also asked to rate on a 7 -point scale $(1=$ not informative at all, $7=$ very informative) how informative the category labels were. To test the alternative account that categories might contribute to choosers' satisfaction by informing their preference construction, participants were asked on 7-point scales ( $1=$ not at all, $7=$ very much), "To what extent did the category labels on the menu help you identify the best option?" and "To what extent did the category labels on the menu help you find the best option for you?" These items were averaged to create the preference identification index $(\alpha=.95)$.

\section{Results}

Manipulation Check. A 2 (chooser type) $\times 4$ (category) ANOVA conducted on the perceived informativeness of the category labels revealed that the categorization manipulation was successful. The results showed a main effect of category condition $(F(1,121)=5.00, p<.01)$ and no interaction effect $(F(1,121)=.40, \mathrm{NS})$. Pairwise comparisons revealed that the attribute-based category labels $(M=4.10)$ were perceived to be more informative than the no-category condition $(M=2.48 ; p<.001)$, the coffeeshop-based category labels $(M=3.31 ; p<.10)$, or the alphabet-based category labels $(M=2.87 ; p<.01)$. The coffee-shop-based labels and the alphabet-based labels did not significantly differ in their perceived informativeness $(p>$ $.10)$.

Hypothesis Testing. Irrespective of the information contained in the category labels, categorization led to greater chooser satisfaction than did no categorization, but only for preference constructors. For preference matchers, the mere presence of categories did not affect their satisfaction with their chosen coffee. A 2 (chooser type) $\times 4$ (category) ANOVA was conducted on choosers' outcome satisfaction, revealing only a significant interaction $(F(3,124)=2.70$, $p<.05)$. Planned contrasts showed that in the no-catego- rization condition, preference constructors $(M=3.53)$ were significantly less satisfied than preference matchers $(M=4.80 ; F(1,124)=7.14, p<.01)$, whereas in each of the three categorization conditions preference constructors and preference matchers did not significantly differ in their levels of outcome satisfaction ( $p$ 's $>.10)$. Furthermore, in support of hypothesis 2, pairwise comparisons showed that for preference constructors, no categories $(M=3.53)$ led to significantly lower outcome satisfaction than did the attribute-based category labels $(M=4.47 ; p<.05)$, the coffee-shop-based category labels $(M=4.73 ; p<.05)$, or the alphabet-based category labels $(M=4.87 ; p<.01)$. The three categorization conditions did not significantly differ from one another ( $p$ 's > .10). For preference matchers, however, neither the presence of categories nor the content of the category labels significantly influenced their outcome satisfaction (although there was a marginally significant difference between the attribute-based label condition and the coffee-shop-based label condition, $p<.10$ ). See table 2 for a listing of the means and standard deviations.

Categorization showed a similar pattern of effects on choosers' perceptions of variety. For preference constructors (but not for preference matchers), categories led to greater perceptions of variety, irrespective of the content of the category labels. A 2 (chooser type) $\times 4$ (category) ANOVA was conducted on perceived variety, revealing only a significant interaction effect $(F(3,124)=2.79, p<.05)$. Planned contrasts showed that in the no-categorization condition, preference constructors $(M=3.77)$ perceived significantly less variety than did preference matchers $(M=$ 4.84; $F(1,124)=7.52, p<.01)$, whereas in each of the three categorization conditions preference constructors and preference matchers did not significantly differ in their levels of perceived choice ( $p$ 's $>.10$ ). Pairwise comparisons showed that for preference constructors, no categories $(M=3.77)$ led to significantly lower perceived variety than did the attribute-based category labels $(M=4.75 ; p<.05)$, the coffee-shop-based category labels $(M=5.04 ; p<.01)$, or the alphabet-based category labels $(M=4.71 ; p<.05)$. The three categorization conditions did not significantly differ from one another ( $p$ 's $>.10)$. For preference matchers, there were no significant differences across the categorization conditions ( $p$ 's $>.10)$. 
Categorization did not similarly contribute to choosers' preference identification; mere categorization did not facilitate preference constructors' ability to identify the best option. A 2 (chooser type) $\times 4$ (category) ANOVA was conducted on the preference identification index, revealing only a main effect of category $(F(3,121)=3.75, p<.05)$. Pairwise comparisons showed that for preference constructors, the attribute-based category labels $(M=4.03)$ helped participants identify their preferred options significantly more than did the no-category condition $(M=2.36 ; p<.01)$, the coffee-shop-based category labels $(M=2.50 ; p<.05)$, and the alphabet-based category labels $(M=2.47 ; p<.05)$. For preference matchers, there were no significant differences between the category conditions ( $p$ 's $>.10)$.

Process Testing. To examine how mere categorization increased preference constructors' choice satisfaction, two sets of mediation analyses were conducted among these choosers. The first tested the hypothesized role of perceived variety, and the second tested the alternative account of preference identification. First, to test the role of perceived variety, satisfaction was regressed on the presence of categories $(\beta=.35, t=3.02, p<.01)$. Next, perceived variety was regressed on the presence of categories $(\beta=$ $.37, t=3.22, p<.01)$, and then satisfaction was regressed on perceived variety $(\beta=.37, t=3.15, p<.01)$. The effect of the presence of categories on satisfaction $(\beta=.25$, $t=2.06, p<.05$ ) was found to significantly decrease, while the effect of perceived variety remained significant $(\beta=$ $.27, t=2.23, p<.05$; Sobel $z=2.28, p<.05)$. Supporting hypothesis $1 \mathrm{~b}$, this suggests that the positive effect of the mere presence of categories on preference constructors' satisfaction is mediated by perceived variety. Next, to test whether preference identification also has a significant effect on preference constructors' satisfaction, the same set of analyses was conducted, with perceived variety replaced with the preference identification index. However, the insignificant effect of the presence of categories on choosers' ability to identify their preferred options $(\beta=.17, t=1.33, p>$ $.10)$ and the marginal effect of preference identification on outcome satisfaction $(\beta=.21, t=1.69, p<.10)$ suggested that preference identification did not mediate the effect.

With evidence that the mere presence of categories leads to increased chooser satisfaction by increasing perceptions of variety in the assortment, an additional set of mediation analyses examined why mere variety leads to greater satisfaction. Among preference constructors, satisfaction was first regressed on perceived variety $(\beta=.35, t=4.28$, $p<.001)$. Next, feelings of self-determination were regressed on perceived variety $(\beta=.30, t=3.55, p=.001)$, and then satisfaction was regressed on feelings of self-determination $(\beta=.42, t=5.20, p<.001)$. In support of hypothesis 3 , the effect of perceived variety $(\beta=.25, t=3.09, p<.01)$ significantly decreased, while the effect of self-determination remained highly significant $(\beta=.34, t=4.21, p<$ .001 ; Sobel $z=2.90, p<.01$ ), suggesting that the positive effect of perceived variety on preference constructors' satisfaction is mediated by feelings of self-determination.
In sum, these results suggest that for preference constructors, the mere presence of categories in an assortment leads to greater perceptions of variety, which lead to greater feelings of self-determination, which result in greater satisfaction with the chosen options. This effect is one of perception, driven by mere categorization and variety, rather than one of preference identification. Preference matchers, on the other hand, do not rely on the display cue of categorization to derive satisfaction from the process of choosing.

\section{GENERAL DISCUSSION}

The results of a preliminary field study and two lab experiments show that a display cue incidental to the choosing process can influence consumers' satisfaction with the choices they make. We found that the number of categories partitioning an assortment leads consumers to feel more satisfied with their chosen option, even when those categories do not provide information about the options in the assortment. Such findings reveal that the positive effect of categorization is not only a cognitive process in which the content of category labels helps consumers identify their preferred option. The effect is also a perceptual process in which consumers infer differences in the available options through the mere presence of categories. A greater number of categories increases perceptions of variety, greater perceptions of variety increases self-determination, and greater self-determination increases consumers' satisfaction. This effect is mitigated among preference matchers.

Identification of the mere categorization effect contributes to the growing amount of research demonstrating the impact of the "mere" presence of particular factors on consumers" judgments and behavior. In the mere measurement effect, measuring consumers' behavioral intentions is shown to influence their subsequent likelihood of engaging in that behavior (e.g., Janiszewski and Chandon 2007). In the mere exposure effect, exposing consumers to a brand name is shown to instill more positive brand attitudes (Janiszewski 1993; Zajonc 1980). In the mere social presence effect, the presence of another shopper in a store is shown to generate negative emotions in consumers (Argo, Dahl, and Manchanda 2005). In the mere accessibility effect, making positive information easy to retrieve is shown to prompt more positive evaluations (Menon and Raghubir 2003). In the mere categorization effect, we show that the presence of category labels in an option display leads to greater consumer satisfaction. As in the other "mere" effects, the mechanism underlying our categorization effect is neither cognitive nor expected.

Our study of the mere categorization effect has also yielded intriguing theoretical implications, potentially offering additional insight into the "paradox of choice" (Iyengar and Lepper 2000; Schwartz 2004). On the one hand, retailers appeal to consumers' desire for variety by supplying them with an ever-increasing number of choices (Kahn 1995; McAlister and Pessemier 1982). On the other hand, extensive choice sets are associated with decreases in both consumer satisfaction and likelihood to purchase because of 
consumers' limited cognitive ability to process the large amount of information that accompanies extensive choice sets (Benartzi and Thaler 2002; Chernev 2003a, 2003b; Iyengar and Lepper 2000; Iyengar, Wells, and Schwartz 2006; Miller 1956; Schneider 1998; Schwartz 2000; Simon 1955; Solomon, Holmes, and McCaul 1980). Our results propose a moderator to these instances of "choice overload." Specifically, the mere presence of categories in an extensive choice set might serve to regain choosers' satisfaction by helping those who are most susceptible to the detriments of too much choice (Chernev 2003a, 2003b) discern differences among the available options. That is, because categories allow choosers to perceive the variety available in extensive choice sets, an increased number of categories may be able to alleviate the detrimental effects of choice overload.

To explore this possibility that the mere presence of categories could eliminate the drop in satisfaction between choosers faced with overwhelming extensive choice sets and choosers faced with cognitively manageable limited choice sets, we conducted a study using a similar paradigm as the coffee study, but we included a limited choice set condition. As in experiment 2, participants $(N=121,47 \%$ women, age range $18-75$ years, $M=28$ years) were presented with a menu of coffee options. But in addition to manipulating the presence of categories (zero vs. 10) and the informativeness of the category labels (attribute-based vs. fabricated coffee-shop-based), we also manipulated the number of options presented by including a condition with five uncategorized options. In line with previous research (Chernev 2003a, 2003b), we found that preference constructors presented with 50 uncategorized options $(M=2.70)$ were significantly less satisfied with their coffee selections than were either preference constructors presented with five options $(M=4.09 ; F(1,55)=11.34, p=.001)$ or preference matchers presented with 50 uncategorized options $(M=$ 5.07; $F(1,55)=21.50, p<.001)$. More important, we found that the mere presence of categories (irrespective of whether the category labels were informative) reduced this detrimental effect by signaling greater variety in the large assortment. See table 3 for the results.

This article offers two important insights. First, our proposed mechanism suggests that categories function differently than screening devices such as those investigated by
Diehl et al. (2003). Diehl et al. found that access to a screening device, which rank orders a subset of the available alternatives by attribute importance, leads to better-quality choices. Yet the results of experiment 2-in which categories not containing attribute information positively influenced preference constructors' satisfaction-distinguish our proposed effect of categories as a visual display cue from other information-based effects in which categories delineate smaller consideration sets that allow choosers to narrow their focus to the options offering their preferred combination of attributes.

Second, we evaluate decision outcomes by concentrating on consumers' subjective feelings of satisfaction that result from a sense of self-determination. In prior work (Diehl et al. 2003), screening devices helped participants choose objectively "better" outcomes. We propose a distinct, experiential effect by which consumers are more satisfied as long as they feel that they have made a choice. Whether the chosen outcome is objectively better (possessing an ideal combination of attributes) may be irrelevant as long as choosers perceive themselves to have attained the option they believe suits them best. The design for experiment 2 made possible this distinction between subjectively and objectively preferred outcomes. Even though all participants were unknowingly given the exact same coffee flavor to taste and evaluate, participants experienced their coffee as personally chosen. Therefore, we were able to precisely test the influence of the choosing experience on choosers' evaluations of their chosen outcomes, irrespective of the outcome's objective qualities. This investigation reveals a novel role for categories. Even without providing an attributebased screening mechanism or ensuring objectively better outcomes, categories are able to highlight the experiential variance among options that satisfy consumers. In light of these findings, we can add categories to the list of display cues that influence consumers' perceptions of variety (Broniarczyk et al. 1998; Hoch et al. 1999; Kahn and Wansink 2004; Morales et al. 2005) and improve novice choosers' decision-making experiences in the face of an overwhelming number of options (Chernev 2003a, 2003b).

The findings of this investigation are of relevance to marketing practitioners as well. We asked 15 magazine exec-

TABLE 3

COFFEE STUDY RESULTS

\begin{tabular}{|c|c|c|c|c|c|c|c|c|}
\hline \multirow[b]{3}{*}{ Chooser type } & \multicolumn{2}{|c|}{ Five options } & \multicolumn{6}{|c|}{ Fifty options } \\
\hline & \multicolumn{2}{|c|}{ Zero categories } & \multicolumn{2}{|c|}{ Zero categories } & \multicolumn{2}{|c|}{$\begin{array}{l}\text { Ten attribute-based } \\
\text { categories }\end{array}$} & \multicolumn{2}{|c|}{$\begin{array}{c}\text { Ten coffee-shop-based } \\
\text { categories }\end{array}$} \\
\hline & $\begin{array}{l}\text { Preference } \\
\text { constructor }\end{array}$ & $\begin{array}{l}\text { Preference } \\
\text { matcher }\end{array}$ & $\begin{array}{l}\text { Preference } \\
\text { constructor }\end{array}$ & $\begin{array}{l}\text { Preference } \\
\text { matcher }\end{array}$ & $\begin{array}{l}\text { Preference } \\
\text { constructor }\end{array}$ & $\begin{array}{l}\text { Preference } \\
\text { matcher }\end{array}$ & $\begin{array}{l}\text { Preference } \\
\text { constructor }\end{array}$ & $\begin{array}{l}\text { Preference } \\
\text { matcher }\end{array}$ \\
\hline Satisfaction & $4.09^{a}(1.16)$ & $4.63(1.24)$ & $2.70^{\mathrm{a}, \mathrm{b}, \mathrm{c}}(1.14)$ & $5.07^{\text {b,d }}(1.68)$ & $3.46^{\mathrm{e}}(1.49)$ & $4.55^{\mathrm{e}}(1.25)$ & $3.76^{c}(1.09)$ & $3.88^{d}(1.77)$ \\
\hline Perceived variety & $4.67^{\mathrm{a}}(1.09)$ & $4.44(1.13)$ & $2.88^{a, b, c, d}(.99)$ & $5.25^{\mathrm{b}, \mathrm{e}}(1.14)$ & $4.96^{c}(1.33)$ & $4.64^{f}(1.29)$ & $4.42^{\mathrm{d}}(1.18)$ & $3.64^{\mathrm{e}, \mathrm{f}}(.95)$ \\
\hline
\end{tabular}


utives which has a stronger effect on magazine customers' satisfaction: the number of different categories or the number of different magazines. The majority (87\%) of these experts concluded that the number of different categories is less important than the number of different magazines. Yet the combined findings from these field and laboratory studies suggest that the number of categories can significantly affect customers' satisfaction, perhaps even more so than the actual number of options present.

Categorization can therefore benefit practitioners by providing an alternative to option reduction in alleviating the effects of choice overload. The mere presence of categories can assist consumers in visually parsing choice sets into more groupings, enhancing their perceptions of the variety among options. In other words, categorization could transform "too much choice" into just the right amount by better enabling consumers to obtain value from large assortments. This same mechanism could also be used to efficiently address retailers' and marketers' opposing concerns of providing more options to satisfy consumers' desire for variety, by instead using categories to highlight the existing variety in the assortment.

\section{APPENDIX}

COFFEE MENUS PRESENTED IN EXPERIMENT 2

FIGURE A1

NO CATEGORIES

\section{Co Coffee Menu}

Arabian Mocha Java
Gaia Blend
Holiday Blend
Gold Coast Blend
Kona Coffee
Sierra Dorada Blend
Top Blend
Guatemala
Christmas
Rift Valley Blend
Costa Rica
Cascada
House Blend
Blend 101
Breakfast Blend
House Blend Decaf
Light Note Blend
Aged Sumatra
Gazebo Blend
Sumatra
Kenya
Carabobo
Garuda Blend
Sulawesi-Kalosi
Colombia Narino Supremo

Espresso Forte

Fair Trade Blend Ethiopian Fancy Yukon Blend Java Dutch Estate

French Roast

Italian Roast

Espresso Roast

Senseo Douwe

Black Satin

Brazilian Santos

India Malabar Monsoon

Café Estima Blend

Major Dickason's Blend

New Guinea

Guatemala Antigua

La Azulita

Ethiopia Sidamo

Shade Grown Mexico

Santo Cristo

Rancho Mathilde

Komodo Dragon Blend

Sulawesi

Caffe Verona

San Francisco Blend
FIGURE A2

TEN ATTRIBUTE-BASED CATEGORIES

\section{Coffee Menu}

-Complex•

Arabian Mocha Java

Gaia Blend

Holiday Blend

Gold Coast Blend

Kona Coffee

-Spicy

Sierra Dorada Blend

Top Blend

Guatemala

Christmas

Rift Valley Blend

-Smoky•

Costa Rica

Cascada

Café Estima Blend

Brazilian Santos

India Malabar Monsoon

-Sweet

Aged Sumatra
Gazebo Blend

Sumatra

Kenya

Carabobo

-Nutty•

Garuda Blend

Sulawesi-Kalosi

Sulawesi-Kalosi
Colombia Narino Supremo

Caffe Verona

San Francisco Blend
-Tangy•

Espresso Forte

Fair Trade Blend

Ethiopian Fancy

Yukon Blend

Java Dutch Estate

-Dark Roast.

French Roast

Italian Roast

Espresso Roast

Senseo Douwe

Black Satin -Mild.

House Blend

Blend 101

Breakfast Blend

House Blend Decaf Light Note Blend

-Smooth.

Major Dickason's Blend

New Guinea

Guatemala Antigua

La Azulita

-Earthy•

Shade Grown Mexico

Santo Cristo

Rancho Mathilde

Komodo Dragon Blend

Sulawesi 
FIGURE A4

TEN ALPHABET-BASED CATEGORIES
FIGURE A3

TEN COFFEE-SHOP-BASED CATEGORIES

\section{Coffee Menu}

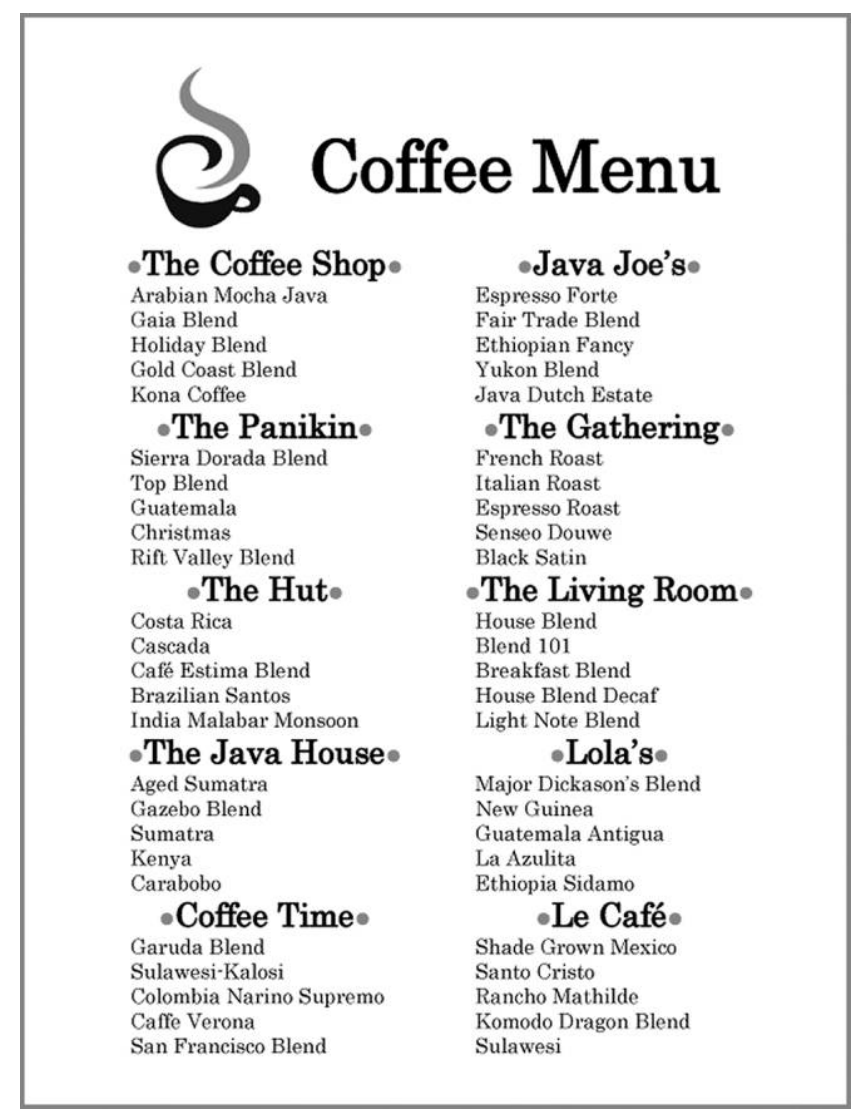

\section{REFERENCES}

Alba, Joseph and Wesley Hutchinson (1987), "Dimensions of Consumer Expertise," Journal of Consumer Research, 13 (March), 411-54.

Alba, Joseph, Wesley Hutchinson, and John Lynch (1991), "Memory and Decision Making," in Handbook of Consumer Theory Research, ed. Harold Kassarjian and Thomas Robertson, Englewood Cliffs, NJ: Prentice-Hall, 1-49.

Argo, Jennifer L., Darren W. Dahl, and Rajesh V. Manchanda (2005), "The Influence of a Mere Social Presence in a Retail Context," Journal of Consumer Research, 32 (September), 207-12.

Benartzi, Shlomo and Richard Thaler (2002), "How Much Is Investor Autonomy Worth?" Journal of Finance, 57 (August), 1593-1616.

Bettman, James (1979), An Information Processing Theory of Consumer Choice, Reading, MA: Addison-Wesley.

Bettman, James, Mary Frances Luce, and John Payne (1998), "Constructive Consumer Choice Processes," Journal of Consumer Research, 25 (December), 187-217.

Broniarczyk, Susan, Wayne Hoyer, and Leigh McAlister (1998), "Consumers' Perceptions of the Assortment Offered in a Gro- cery Category: The Impact of Item Reduction," Journal of Marketing Research, 35 (May), 166-76.

Carpenter, Gregory S., Rashi Glazer, and Kent Nakamoto (1994), "Meaningful Brands from Meaningless Differentiation: The Dependence of Irrelevant Attributes," Journal of Marketing Research, 31 (August), 339-50.

Carpenter, Gregory S. and Kent Nakamoto (1989), "Consumer Preference Formation and Pioneering Advantage," Journal of Marketing Research, 26 (August), 285-98.

Chakravarti, Amitav and Chris Janiszewski (2003), "The Influence of Macro-Level Motives on Consideration Set Composition in Novel Purchase Situations," Journal of Consumer Research, 30 (September), 244-58.

Chernev, Alexander (2003a), "Product Assortment and Individual Decision Processes," Journal of Personality and Social Psychology, 85 (July), 151-62.

(2003b), "When More Is Less and Less Is More: The Role of Ideal Point Availability and Assortment in Consumer Choice," Journal of Consumer Research, 30 (September), 170-83.

Clark, Herbert H. (1985), "Language Use and Language Users," in Handbook of Social Psychology, ed. Gardner Lindzey and Elliot Aronson, New York: Harper \& Row, 179-231.

Coupey, Eloise, Julie Irwin, and John Payne (1998), "Product Cat- 
egory Familiarity and Preference Construction," Journal of Consumer Research, 24 (March), 459-68.

Deci, Edward L., Haleh Eghrari, Brian C. Patrick, and Dean R. Leone (1994), "Facilitating Internalization: The Self-Determination Theory Perspective," Journal of Personality, 62 (March), 119-42.

Deci, Edward L. and Richard M. Ryan (1985), "The General Causality Orientations Scale: Self-Determination in Personality," Journal of Research in Personality, 19 (June), 109-34.

Dhar, Ravi (1997), "Consumer Preference for a No-Choice Option," Journal of Consumer Research, 24 (September), 215-31.

Diehl, Kristin, Laura J. Kornish, and John G. Lynch (2003), "Smart Agents: When Lower Search Costs for Quality Information Increase Price Sensitivity," Journal of Consumer Research, 30 (June), 56-71.

Dodd, Tim, Bruce Pinkleton, and William Gustafson (1996), "External Information Sources of Product Enthusiasts: Differences between Variety Seekers, Variety Neutrals, and Variety Avoiders," Psychology and Marketing, 13 (May), 291-304.

Festinger, Leon (1964), Conflict, Decision and Dissonance, Stanford, CA: Stanford University Press.

Fischhoff, Baruch (1991), "Value Elicitation: Is There Anything in There?" American Psychologist, 46 (August), 835-47.

Fischhoff, Baruch, Paul Slovic, and Sarah Lichtenstein (1980), "Knowing What You Want: Measuring Labile Values," in Cognitive Processes in Choice and Decision Behavior, ed. Thomas S. Wallsten, Hillsdale, NJ: Erlbaum, 117-41.

Grice, H. Paul (1975), "Logic and Conversation," in Syntax and Semantics III: Speech Acts, ed. Peter Cole and Jerry L. Morgan, New York: Academic Press, 41-58.

Hauser, John and Birger Wernerfelt (1990), "An Evaluation Cost Model of Consideration Sets," Journal of Consumer Research, 16 (March), 393-408.

Heit, Evan and Joshua Rubinstein (1994), "Similarity and Property Effects in Inductive Reasoning," Journal of Experimental Psychology: Learning, Memory, and Cognition, 20 (March), 411-22.

Hoch, Stephen, Eric Bradlow, and Brian Wansink (1999), "The Variety of an Assortment," Marketing Science, 18 (4), 52746.

Hoch, Stephen and Young-Won Ha (1986), "Consumer Learning: Advertising and the Ambiguity of Product Experience," Journal of Consumer Research, 13 (September), 221-33.

Hoeffler, Steven and Dan Ariely (1999), "Constructing Stable Preferences: A Look into Dimensions of Experience and Their Impact on Preference Stability," Journal of Consumer Psychology, 8 (2), 113-39.

Howard, John and Jagdish Sheth (1969), The Theory of Buyer Behavior, New York: Wiley.

Huber, Joel and Noreen Kline (1991), "Adapting Cutoffs to the Choice Environment: The Effects of Attribute Correlation and Reliability," Journal of Consumer Research, 18 (December), 346-57.

Iyengar, Sheena S. and Mark R. Lepper (2000), "When Choice Is Demotivating: Can One Desire Too Much of a Good Thing?" Journal of Personality and Social Psychology, 79 (December), 995-1006.

Iyengar, Sheena S., Rachael Wells, and Barry Schwartz (2006), "Doing Better but Feeling Worse: Looking for the 'Best' Job Undermines Satisfaction," Psychological Science, 17 (February), $143-50$.
Janiszewski, Chris (1993), "Preattentive Mere Exposure Effects," Journal of Consumer Research, 20 (December), 376-92.

Janiszewski, Chris and Elise Chandon (2007), "Transfer Appropriate Processing, Response Fluency, and the Mere Measurement Effect," Journal of Marketing Research, 44 (May), 309-23.

Johnson, Eric and John Payne (1985), "Effort and Accuracy in Choice," Management Science, 31 (April), 395-414.

Kahn, Barbara (1995), "Consumer Variety-Seeking among Goods and Services: An Integrative Review," Journal of Retailing and Consumer Services, 2 (July), 139-48.

Kahn, Barbara and Brian Wansink (2004), "The Influence of Assortment Structure on Perceived Variety and Consumption Quantities," Journal of Consumer Research, 30 (March), 519-33.

Lassaline, Mary E. (1996), "Structural Alignment in Induction and Similarity," Journal of Experimental Psychology: Learning, Memory, and Cognition, 22 (May), 754-70.

Levin, Irwin and Gary Gaeth (1988), "How Consumers Are Affected by the Framing of Attribute Information Before and After Consuming the Product," Journal of Consumer Research, 15 (December), 374-78.

Lingle, John H. and Thomas M. Ostrom (1979), "Retrieval Selectivity in Memory-Based Impression Judgments," Journal of Personality and Social Psychology, 37 (February), 180-94.

Lynch, John G., Jr., Dipankar Chakravarti, and Anusree Mitra (1991), "Contrast Effects in Consumer Judgments: Changes in Mental Representations or in the Anchoring of Rating Scale?" Journal of Consumer Research, 18 (December), 284-97.

Lynch, John G., Jr., Howard Marmorstein, and Michael F. Weigold (1988), "Choices from Sets including Remembered Brands: Use of Recalled Attributes and Prior Overall Evaluations," Journal of Consumer Research, 15 (September), 169-84.

McAlister, Leigh and Edgar Pessemier (1982), "Variety Seeking Behavior: An Interdisciplinary Review," Journal of Consumer Research, 9 (December), 311-22.

Menon, Geeta and Priya Raghubir (2003), "Ease-of-Retrieval as an Automatic Input in Judgments: A Mere-Accessibility Framework?" Journal of Consumer Research, 30 (September), 230-43.

Miller, George (1956), “The Magical Number Seven, Plus or Minus Two: Some Limits on Our Capacity for Information Processing," Psychological Review, 63 (March), 81-97.

Morales, Andrea, Barbara E. Kahn, Leigh McAlister, and Susan Broniarczyk (2005), "Perceptions of Assortment Variety: The Effects of Congruency between Consumers' Internal and Retailers' External Organization," Journal of Retailing, 81 (2), 159-69.

Nedungadi, Prakash (1990), "Recall and Consumer Consideration Sets: Influencing Choice without Altering Brand Evaluations," Journal of Consumer Research, 17 (December), 263-76.

Ratneshwar, S. and Allan D. Shocker (1991), "Substitution in Use and the Role of Usage Context in Product Category Structures," Journal of Marketing Research, 28 (August), 281-95.

Roberts, John H. and James M. Lattin (1991), "Development and Testing of a Model of Consideration Set Composition," Journal of Marketing Research, 28 (November), 429-40.

Rosch, Eleanor (1976), "Basic Objects in Natural Categories," Cognitive Psychology, 8 (July), 382-439. (2002), "Principles of Categorization," in Foundations of 
Cognitive Psychology: Core Readings, ed. Daniel Levitin, Cambridge, MA: MIT Press, 251-70.

Rosen, Sherwin (1978), "Advertising, Information, and Product Differentiation," in Issues in Advertising, ed. David Tuerck, Washington, DC: American Enterprise Institute, 161-91.

Russo, Edward and France Leclerc (1994), "An Eye-Fixation Analysis of Choice Processes for Consumer Nondurables," Journal of Consumer Research, 21 (September), 274-90.

Ryan, Richard M. (1982), "Control and Information in the Intrapersonal Sphere: An Extension of Cognitive Evaluation Theory," Journal of Personality and Social Psychology, 43 (September), 450-61.

Ryan, Richard M. and Edward Deci (2000), "Self-Determination Theory and the Facilitation of Intrinsic Motivation, Social Development, and Well-Being," American Psychologist, 55 (January), 68-78.

- (2006), "Self-Regulation and the Problem of Human Autonomy: Does Psychology Need Choice, Self-Determination, and Will?" Journal of Personality, 74 (December), 1557-85.

Ryan, Richard M., Richard Koestner, and Edward Deci (1991), "Varied Forms of Persistence: When Free-Choice Behavior Is Not Intrinsically Motivated," Motivation and Emotion, 15 (September), 185-205.

Schmitt, Bernd and Shi Zhang (1998), "Language Structure and Categorization: A Study of Classifiers in Consumer Cognition, Judgment, and Choice," Journal of Consumer Research, 25 (September), 108-22.

Schneider, Carl (1998), The Practice of Autonomy: Patients, Doctors, and Medical Decisions, Oxford: Oxford University Press.
Schwartz, Barry (2000), "Self-Determination: The Tyranny of Freedom," American Psychologist, 55 (January), 79-88. (2004), The Paradox of Choice: Why More Is Less, New York: HarperCollins.

Simon, Herbert A. (1955), "A Behavioral Model of Rational Choice," Quarterly Journal of Economics, 69 (February), 99-118.

Sloutsky, Vladimir (2003), "The Role of Similarity in the Development of Categorization," Trends in Cognitive Sciences, 7 (June), 246-51.

Solomon, Sheldon, David S. Holmes, and Kevin D. McCaul (1980), "Behavioral Control over Aversive Events: Does Control That Requires Effort Reduce Anxiety and Psychological Arousal?" Journal of Personality and Social Psychology, 39 (October), 729-36.

Tversky, Amos and Eldar Shafir (1992), "Choice under Conflict: The Dynamics of Deferred Decision," Psychological Science, 3 (May), 358-61.

Wright, Peter (1975), "Consumer Choice Strategies: Simplifying vs. Optimizing," Journal of Marketing Research, 12 (February), 60-67.

Zajonc, Robert B. (1980), "Feeling and Thinking: Preferences Need No Inference," American Psychologist, 35 (February), 151-71.

Zhang, Shi and Gavan J. Fitzsimons (1999), "Choice-Process Satisfaction: The Influence of Attribute Alignability and Choice Limitation," Organizational Behavior and Human Decision Processes, 77 (March), 192-214. 